
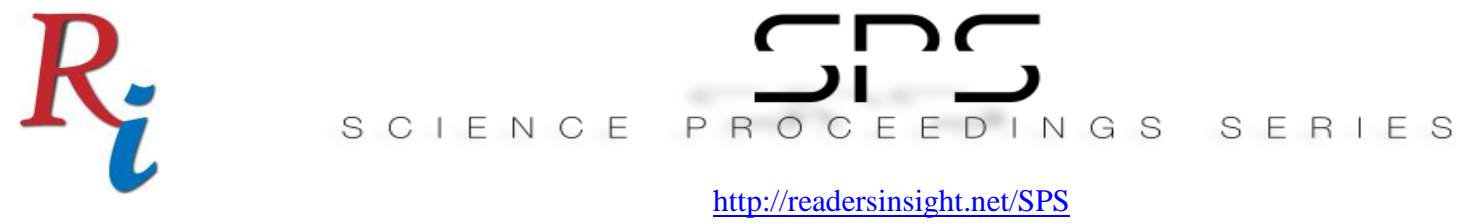

\title{
A ReVIeW on Golden SpeCies of ZingIBERACEAE FAMILY: GENUS CURCUMA
}

\author{
Abdul Mubasher Furmuly \\ Department of Analytical Chemistry, Faculty of Chemistry \\ Kabul University, 1001 Kabul, Kabul \\ Afghanistan \\ mubasher.furmuly@yahoo.com \\ Najiba Azemi* \\ Department of Chemistry, Faculty of Education \\ Balkh University, 1701 Balkh, Mazar-i-Sharif \\ Afghanistan \\ najibaazemi@yahoo.com
}

*Corrosponding author's Email: najibaazemi@yahoo.com

Peer-review under responsibility of 4th Asia International Multidisciplinary Conference 2020 Scientific Committee

http://connectingasia.org/scientific-committee/

(C) 2020 Published by Readers Insight Publisher,

Office \# 6, First Floor, A \& K Plaza, Near D Watson, F-10 Markaz, Islamabad. Pakistan,

editor@readersinsight.net

This is an open access article under the CC BY-NC-ND license (http://creativecommons.org/licenses/by-nc-nd/4.0/). 


\section{$R_{i}$}

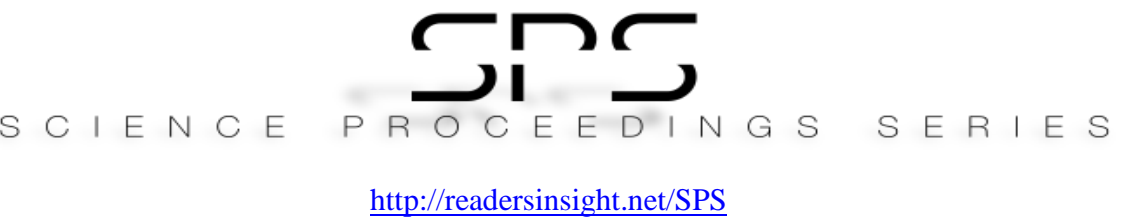

\section{A b s t r a c t}

The genus Curcuma pertains to the Zingiberaceae family and consists of 70-80 species of perennial rhizomatous herbs. This genus originates in the Indo-Malayan region and it is broadly spread all over the world across tropical and subtropical areas. This study aims to provide more information about morphological features, biological activities, and phytochemicals of genus Curcuma for further advanced research. Because of its use in the medicinal and food industries, Curcuma is an extremely important economic genus. Curcuma species rhizomes are the source of a yellow dye and have traditionally been utilized as spices and food preservatives, as a garnishing agent, and also utilized for the treatment of various illnesses because of the chemical substances found in them. Furthermore, Because of the discovery of new bioactive substances with a broad range of bioactivities, including antioxidants, antivirals, antimicrobials and antiinflammatory activities, interest in their medicinal properties has increased. Lack of information concerning morphological, phytochemicals, and biological activities is the biggest problem that the researcher encountered. This review recommended that collecting information concerning the Curcuma genus may be providing more opportunities for further advanced studies lead to avoid wasting time and use this information for further research on bioactive compounds which are beneficial in medicinal purposes.

\section{Rese a r ch H igh I ight s}

Based on the review, Curcuma species are very important medicinal plants consisting of numerous bioactive compounds. To use these bioactive compounds in medicinal and industrial purposes, isolation and identification of them are required. However, enormous varieties of Curcuma species with chemical components and bioactivities have been reported. There is a lack of literature related to the food and nutritional purposes, health advantage, and cosmetic industries from genus Curcuma. Several types of research on food nutritional and medicinal studies have been investigated by researchers as finding new novel compounds is desirable. This review paper can create opportunities for improvement of new plant nutritional food and medicinal products. Furthermore, lack of systematic information to differentiate plants with their genera is the main problem that researchers encountered to find Curcuma plants inside native countries and pharmacological or phytochemical investigations, although many species have been recognized in India. Besides, this study provides more beneficial information in pharmaceutical alternatives to remedy more illnesses. 

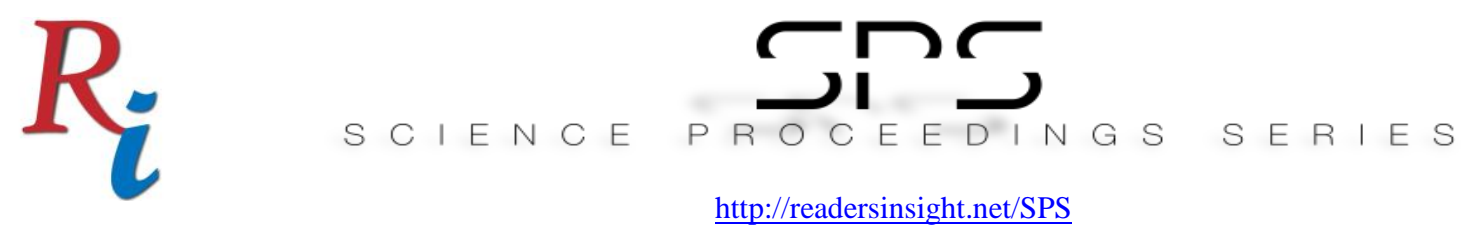

\section{Graphical A bstract}

\section{Morphology:}

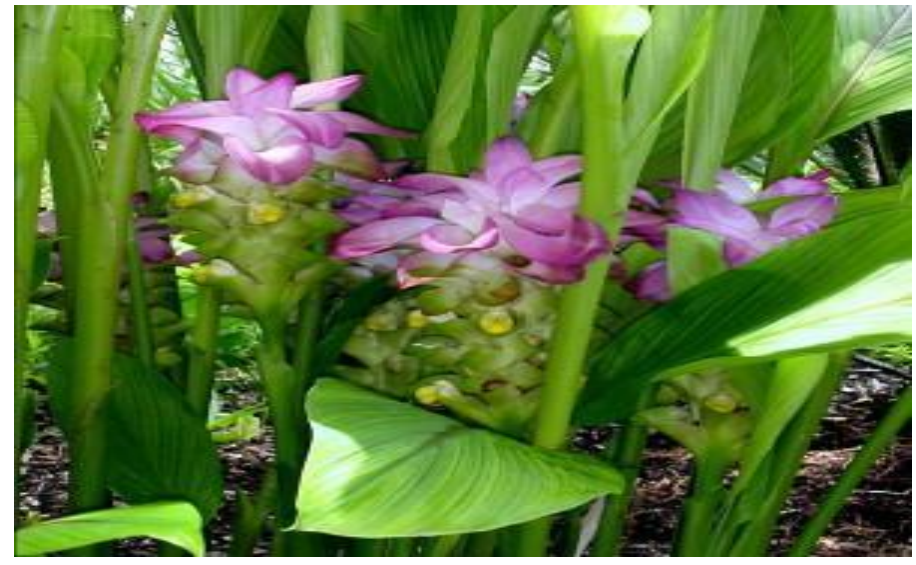

The whole plant of Curcuma Longa

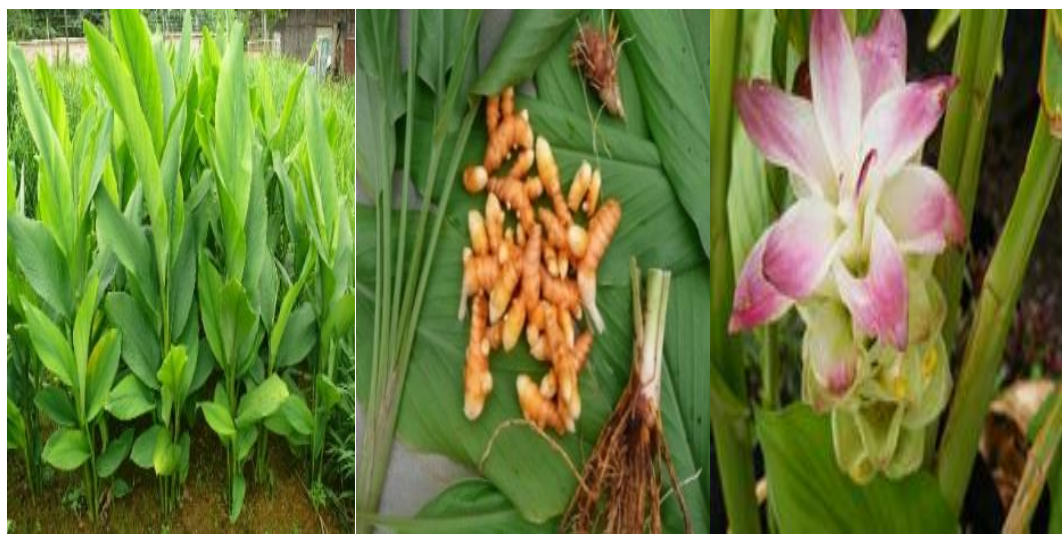

The leaves, rhizomes, and flower of Curcuma Longa

\section{Biological Activities:}

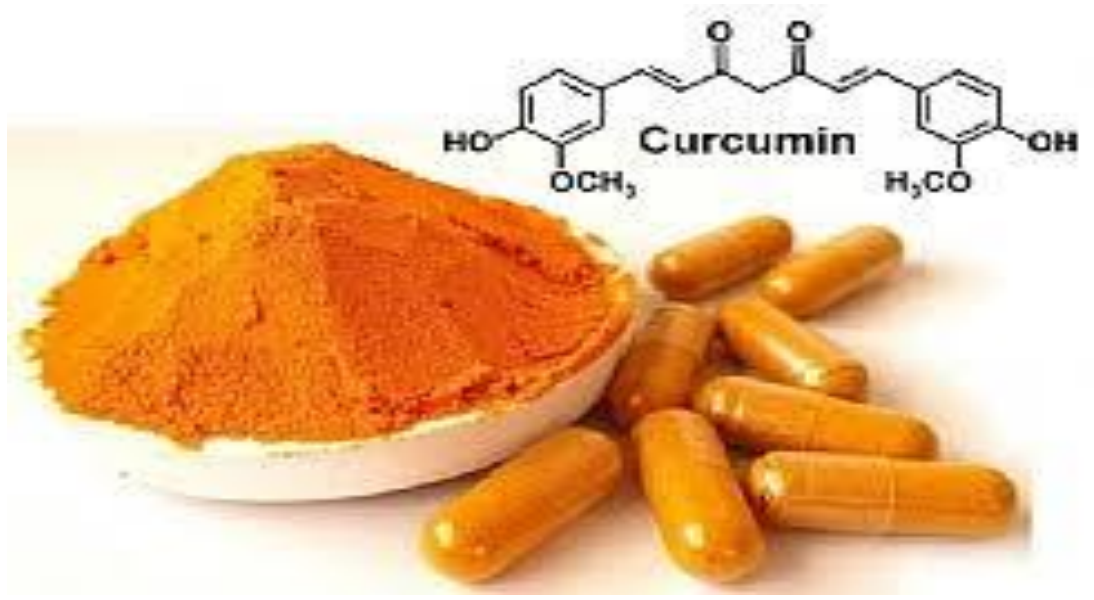




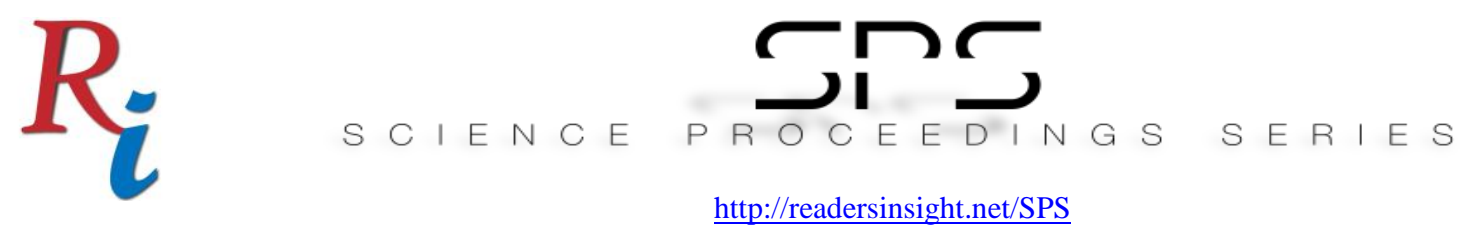

\section{Pharmacology:}

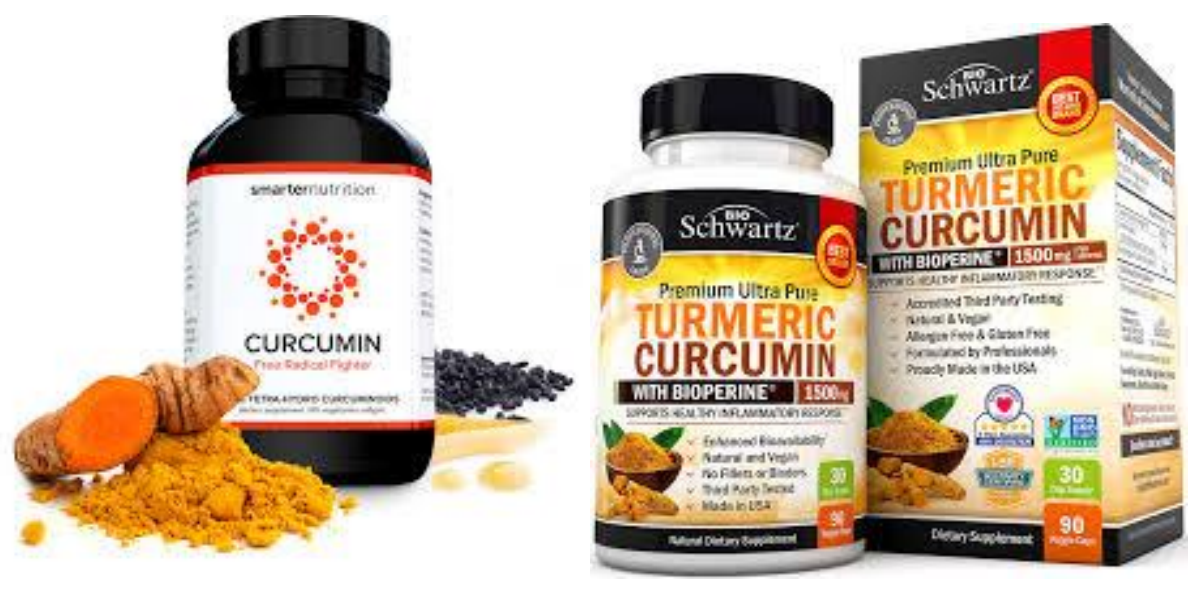

\section{Usage in the Different Part of Industry:}
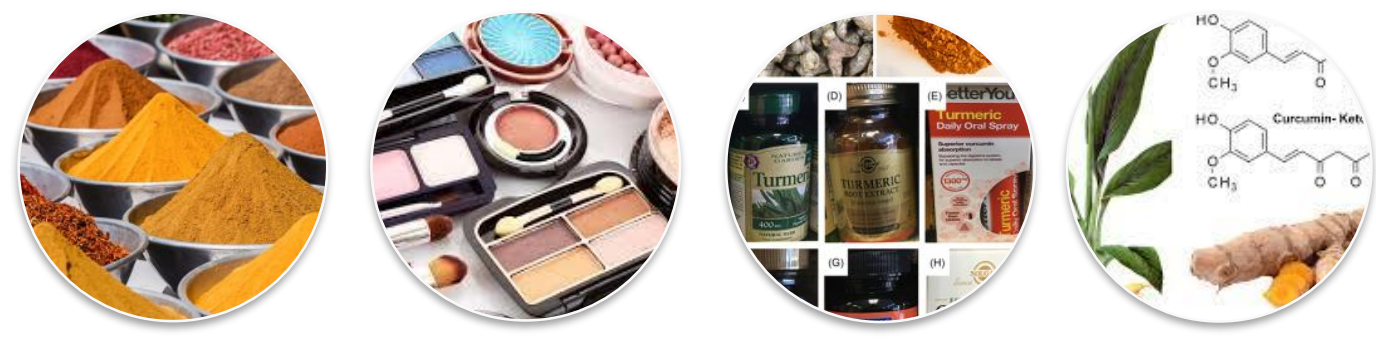

\section{Research Objectives}

Curcuma species have been used in Indian and Southeast Asian traditional medicine to treat numerous human illnesses, and are supposed to have many organic activities. Turmeric (C. longa) is an effective yellow coloring source [3]. In many Asian countries, different parts of such species of plants were consumed either cooked or raw as vegetables [1]. Besides, they are also found healthy foods in nutrition. Since turmeric plants provide a rich power supply of carbohydrates, proteins, starch, fats, minerals, and vitamins. Moreover, they utilized for the remedy of different ailments such as hepatic disorders, skin diseases, diabetes, chest pain, blood purifier, enlarged liver, cough, stomach ulcer, spleen, boils, and rheumatism[4] Because of its promising potential and a wide variety of uses, plants belonging to the Curcuma genus are gaining popularity worldwide and have been subjected to many investigations and explorations in the last years. Therefore, appropriate physicochemical and morphological recognition is required, although, still not being investigated systematically. This research aims to gain an overall overview of morphology, pharmacology, and phytochemistry of the genus Curcuma. This review would be used to more investigation in the food supplements, cosmetics, and medicinal industries. 


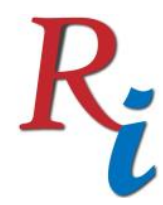

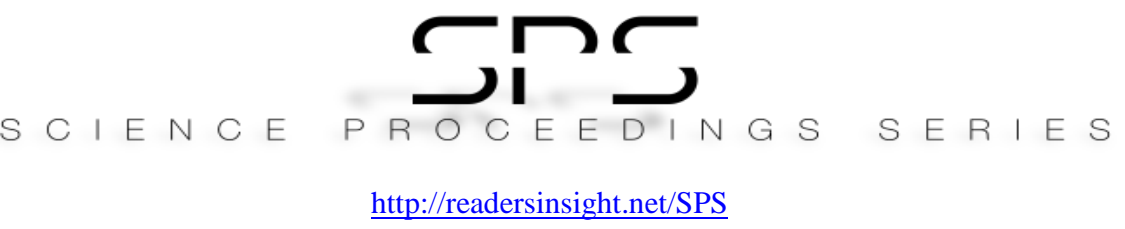

\section{Methodology}

This is a review paper and as it is usual all information has been collected from papers such as indexed Scopus journal, science direct, and so on.

\section{Results}

Based on the review, Curcuma species are very important medicinal plants consisting of numerous bioactive compounds. To use these bioactive compounds in medicinal and industrial purposes, isolation and identification of them are required. However, enormous varieties of Curcuma species with chemical components and bioactivities have been reported. There is a lack of literature related to the food and nutritional purposes, health advantage, and cosmetic industries from genus Curcuma. Several types of research on food nutritional and medicinal studies have been investigated by researchers as finding new novel compounds is desirable [5]. This review paper can create opportunities for improvement of new plant nutritional food and medicinal products. Furthermore, lack of systematic information to differentiate plants with their genera is the main problem that researchers encountered to find Curcuma plants inside native countries and pharmacological or phytochemical investigations, although many species have been recognized in India. Besides, this study provides more beneficial information in pharmaceutical alternatives to remedy more illnesses.

\section{Findings}

The family of gingers or Zingiberaceae contains more than 1,500 species in 53 genera around the world. The Zingiberaceae family composed of elegant fleshy inflorescences with rhizomatous plants that occur terminally and laterally. Among 120 species, Curcuma is considered the largest genera and commonly utilized as spices, medicinal items, colorants, and ornamental plants [2]. Therefore, the Curcuma genus is standard for its commercial value.Nowadays, Curcuma species gain popularity as they are very useful herbecious plants. From ancient times until now, ther are widely used as handy raw materials in various industerial areas such as food nutritions, cosmetics, and pharmaceutical industries. So that, this research aims to gain an overall overview of morphology, pharmacology, and phytochemistry of the genus Curcuma. This review would be used to more investigation in the food supplements, cosmetics, and medicinal industries.

\section{REFERENCES}




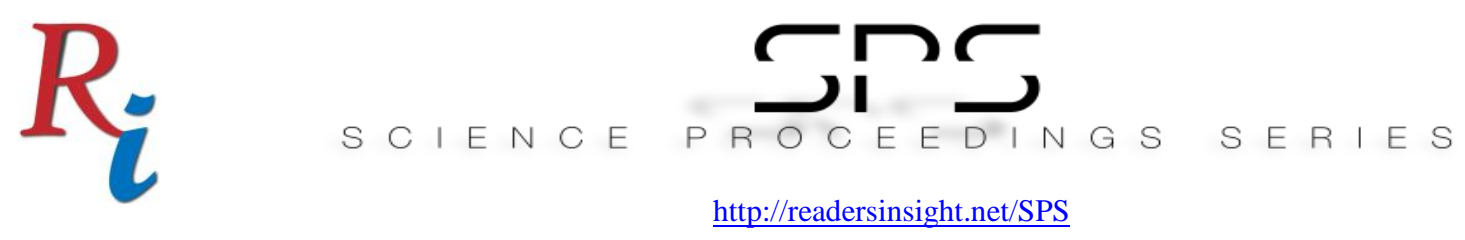

1. Devi, T. I., Devi, K. U., \& Singh, E. (2015). Wild Medicinal Plants in the Hill of Manipur, India: A traditional therapeutic potential. International Journal of Scientific and Research Publications, 5(6), 1-9.

2. Leong-Škorničková, J., Šída, O., Jarolímová, V., Sabu, M., Fér, T., Trávníček, P., \& Suda, J. (2007). Chromosome Numbers and Genome Size Variation in Indian Species of Curcuma (Zingiberaceae). Annals of Botany, 100(3), 505-526. doi:10.1093/aob/mcm144.

3. Srivilai, J., Waranuch, N., Tangsumranjit, A., Khorana, N., \& Ingkaninan, K. (2018). Germacrone and sesquiterpene-enriched extracts from Curcuma aeruginosa Roxb. increase skin penetration of minoxidil, a hair growth promoter. Drug delivery and translational research, 8(1), 140-149.

4. Tewtrakul, S., \& Subhadhirasakul, S. (2007). Anti-allergic activity of some selected plants in the Zingiberaceae family. Journal of ethnopharmacology, 109(3), 535-538.

5. Zhang, C. M., Fan, P. H., Li, M., \& Lou, H. X. (2014). Two new sesquiterpenoids from the rhizomes of Curcuma xanthorrhiza. Helvetica Chimica Acta, 97(9), 1295-1300.

Author's Biography

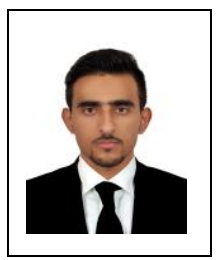

Abdul Mubasher Furmuly obtained his B.Sc in Applied Chemistry in 2014 from Kabul University and Master degree in Chemistry (2020) from Universiti Teknologi Malaysia (UTM), Malaysia. He completed his Master in Analytical Chemistry at the Universiti Teknologi Malaysia (UTM) in 2020. Mubasher started his career as a lecturer at the Department of Chemistry, Faculty of Science, Kabul University in March 2020 after finished his MSc. Currently, he is a Lecturer at the Department of Chemistry, Faculty of Science, Kabul university, Kabul since August 2015. He actively involved in research and teaching activities in Chemistry. He had published one article in an indexed journal during his Master.

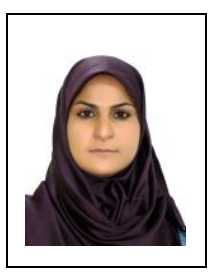

Najiba Azemi obtained her B.Sc in organic chemistry in 2012 from Balkh University and Master degree in organic chemistry (2020) from Universiti Teknologi Malaysia (UTM), Malaysia. Her MSc research was in the area of Natural Products Chemistry. She completed her master in Organic Chemistry at the Universiti Teknologi Malaysia (UTM). Najiba started her career as an assistant lecturer at the Department of Chemistry, Faculty of Education, Balkh University in July 2013 and currently, she is working as a Senior Lecturer. She actively involved in research area and teaching activities in Chemistry with two indexed published papers (Scopus) during her master. 